\title{
The role of galectin-4 in physiology and diseases
}

\author{
Zhan-Qi Cao, Xiu-Li Guo \\ Department of Pharmacology, School of Pharmaceutical Sciences, Shandong University, Jinan 50012, China \\ $\square$ Correspondence: guoxl@sdu.edu.cn (X.-L. Guo) \\ Received January 20, 2016 Accepted March 3, 2016
}

\begin{abstract}
Galectin-4, a tandem repeat member of the $\beta$-galactoside-binding proteins, possesses two carbohydraterecognition domains (CRD) in a single peptide chain. This lectin is mostly expressed in epithelial cells of the intestinal tract and secreted to the extracellular. The two domains have $40 \%$ similarity in amino acid sequence, but distinctly binding to various ligands. Just because the two domains bind to different ligands simultaneously, galectin-4 can be a crosslinker and crucial regulator in a large number of biological processes. Recent evidence shows that galectin-4 plays an important role in lipid raft stabilization, protein apical trafficking, cell adhesion, wound healing, intestinal inflammation, tumor progression, etc. This article reviews the physiological and pathological features of galectin- 4 and its important role in such processes.
\end{abstract}

KEYWORDS galectin-4, lipid raft, crosslinker, intestinal inflammation, tumor progression

\section{INTRODUCTION}

Galectins, composed of 15 members, have been identified as galactoside-binding proteins localized both intra- and extra-cellularly. The galectin family members were widely found in various bionts including vertebrates, invertebrates and even protistans (Cooper and Barondes, 1999). Based on the composition and recognition of the conserved carbohydrate-recognition domain (CRD), galectins are grouped into three subfamilies. The prototype galectins, also called monomer, contain one CRD and include galectins-1, 2, 5, 7, $10,11,13,14$, and 15 . The tandem repeat types contain two distinct but homologous CRDs and include galectins- $4,6,8$, 9 , and 12 . The only chimera type (galectin-3) is defined by a $\mathrm{C}$-terminal $\mathrm{CRD}$ and an elongated $\mathrm{N}$-terminal region that induces the formation of multimers. These galectins are widely present in various types of human cells and participate in various cellular functions, such as cell proliferation, apoptosis, adhesion, signal transduction, immune response, activation of inflammatory response, and regulation of premRNA splicing (Rabinovich, 1999; Cooper, 2002; Danguy et al., 2002; Barrow et al., 2013).

Galectin-4 was first isolated as a $17 \mathrm{kDa}$ protein in the extract of rat small intestine (Leffler et al., 1989). Subsequently, it was identified as a proteolytic fragment of a larger $36 \mathrm{kDa}$ protein by gene cloning (Oda et al., 1993), and found intracellularly, on the cell surface, and in circulation. In vitro, intracellular galectin-4 regulates cell proliferation, apoptosis and differentiation, whereas extracellular galectin-4 mediates intercellular adhesion (Huflejt et al., 1997; Huflejt and Leffler, 2003). Because of no signal sequence for endoplasmatic reticulum transport, the presence of galectin- 4 on the cell surface is a consequence of secretion via nonclassical pathway. This protein specifically binds to $\beta$-galactosides through the two structurally conserved CRDs. As is shown, widely known natural ligands of galectin-4 are human blood group antigens, glycoproteins, mucin like membrane MUC1, glycosphingolipids, and sulfated cholesterol. In addition to $\beta$-galactosides, galectin- 4 could also bind to sulfate. The presence of $3^{\prime}$-sulfation in galactose and lactose was proved to increase the binding affinity to galectin-4 (Ideo et al., 2002; Vokhmyanina et al., 2012). Because of the bivalent or multivalent structure and affinity to above mentioned ligands, galectin-4 plays a crucial role in biochemical regulation and tumor development and progression.

Recently, many studies have been performed with the aim to clarify the interaction between galectin- 4 and physiological regulation, intestinal inflammation and cancer. For example, galectin-4 was identified as a marker in detergent-resistant membranes (DRMs) and a crucial component to stabilize lipid rafts (Delacour et al., 2005). And a contradictory role of galectin-4 on intestinal inflammation was stated to 
exacerbate (Hokama et al., 2004; Hokama et al., 2008) or ameliorate inflammation (Paclik et al., 2008a). Further studies are required to appraise the influence of galectin- 4 in intestinal inflammation. Moreover, galectin-4 has also showed contradictory roles in cancer which may depend on the types of cancer (Rechreche et al., 1997; Belo et al., 2013; Maftouh et al., 2014; Cai et al., 2014; Hayashi et al., 2013; Hippo et al., 2001). This review summarizes the recent progress in understanding the relationship between the structure and the function of galectin- 4 in physiological and pathological processes.

\section{THE MOLECULAR STRUCTURE OF GALECTIN-4 AND BINDING AFFINITY TO LIGANDS}

As a tandem-repeat, human galectin-4 contains two distinct but homologous domains: CRD1 (N-terminal) and CRD2 (C-terminal). These two CRDs have a calculated molecular weight of 16-17 kDa. Each of the CRDs consists of about 130 residues which share $40 \%$ sequence identity, and they are connected by a linker region (Oda et al., 1993; Jiang et al., 1999). This linker region, which is composed of about 30 residues, is rich in proline and glycine, and is sensitive to tissue proteases (Rustiguel et al., 2015). It is believed that galectin- 4 can be a natural crosslinker because of its ability to crosslink two distinct types of ligands (Brewer, 2002). The carbohydrate binding specificities of the two CRDs are quite different and would be expected to show preference for different sets of ligands.

Two CRDs in galectin-4 bind lactose with similar affinity, but their preferences for other glycosphingolipids, oligosaccharides, and glycoprotein are distinctly different. For example, the affinity of CRD2 $\left(K_{D}=2.0 \times 10^{-6} \mathrm{~mol} / \mathrm{L}\right)$ toward $\mathrm{SO}_{3}{ }^{-} \rightarrow 3$ core 1-O-Bn oligosaccharide was higher than that of CRD1 $\left(K_{D}=2.3 \times 10^{-5} \mathrm{~mol} / \mathrm{L}\right)$, whereas CRD1 $\left(K_{D}=8.9 \times\right.$ $\left.10^{-5} \mathrm{~mol} / \mathrm{L}\right)$ showed higher affinity toward Fuca1 $\rightarrow 2-$ Gal $\beta 1 \rightarrow 3 \mathrm{GlcNAc} \beta 1 \rightarrow 3 \mathrm{Gal} \beta 1 \rightarrow 4 \mathrm{Glc}$ than that of CRD2 $\left(K_{D}=\right.$ $1.2 \times 10^{-4} \mathrm{~mol} / \mathrm{L}$ ) (Ideo et al., 2005). CRD2 also showed higher affinity toward 3-O-sulfated glycosphingolipids than that of CRD1 (Ideo et al., 2005). Human CRD2 showed higher binding affinity toward saccharides expressed on $\mathrm{ABO}(\mathrm{H})$ blood group antigens than that exhibited by CRD1 (Vokhmyanina et al., 2012). Oligosaccharide binding profiles showed that the CRD2 in mouse galectin-4 had a high affinity and specificity for A type-2 a-linked N-acetylgalactosamine ( $\alpha-G a I N A c)$ structures, while the CRD1 domain showed a broader affinity compared to CRD2 (Marková et al., 2006). In addition to saccharides, the drastic difference is that CRD1 is able to bind to cholesterol-3-sulfate while CRD2 is incapable (Ideo et al., 2007). An Arg45 in CRD1 was identified as a core for this sulfate recognition, while none of the amino acids in CRD2 domain was identified to directly interact with sulfate groups (Ideo et al., 2007; BumErdene et al. 2015). Moreover, a peptide YVQI in CRD2 was confirmed to bind to Src kinases, therefore regulating the phosphorylation and externalization of galectin-4 (Ideo et al., 2013). However, there is very limited information about the key binding partners underlying binding specificities and key differences for the two domains.

\section{THE PHYSIOLOGICAL FUNCTIONS OF GALECTIN-4}

Galectin-4 enhances the stabilization of lipid raft

Lipid rafts are characterized as heterogeneous and liquid ordered microdomains in the brush border membrane of small intestinal enterocytes (Pike, 2005). Rafts are small sphingolipids-rich and cholesterol-rich platforms in the outer exoplasmic leaflet of the lipid bilayer (Simons and Ehehalt, 2002). Lipid rafts are also known as DRMs because of their common ability to resist solubilization with detergents in various cell membranes (London and Brown, 2000). As a divalent galectin, galectin- 4 was identified as a major component of detergent-insoluble complexes prepared from the small intestine (Danielsen and van Deurs, 1997). In addition, galectin-4 shows the ability to act as a cross-linker, thus indicating that galectin- 4 might play a role in lipid rafts stabilization.

Galectin-4 facilitates stabilization of lipid rafts through formation of homogenous lattices with some glycoproteins and glycolipids (Brewer et al., 2002). Galectin-4 could crosslink a broad range of glycolipids and various brush border proteins on the surface of enterocytes, and form cluster and lattices with them. The externalized galectin- 4 will stay at the cell surface and almost specially localized to the brush border (Danielsen and Hansen, 2008), and target to the outer exoplasmic leaflet of the brush border where it specially associates with lipid rafts and other enzymes, mainly aminopeptidase $\mathrm{N}$ and sucrase-isomaltase (Danielsen and van Deurs, 1997). These enzymes are frequently cleaved and released into the gut lumen by exposing to pancreatic proteinases and lipases. Galectin-4 was reported to protect the brush border enzymes from solubilization by binding simultaneously to membrane glycolipids and enzymes, thus eventually protecting cleaved enzymes releasing into the gut lumen (Danielsen and Hansen, 2008). Generally speaking, at the presence of galectin-4, the lipid rafts are capable of clustering, which means that these proteins and glycolipids are stabilized in stationary microdomains (Fig. 1B). Thus, galectin-4 can be characterized as an organizer/stabilizer within microvillar lipid rafts.

\section{Galectin-4 participates in apical trafficking}

The surface of enterocyte is divided into basolateral domains and apical with distinct compositions and functions. The apical surface contains the proteins required for organ-specific functions while the basolateral surface expresses adhesion molecules and receptors, which creates an asymmetric structure. This asymmetric structure implies a polarized 
A
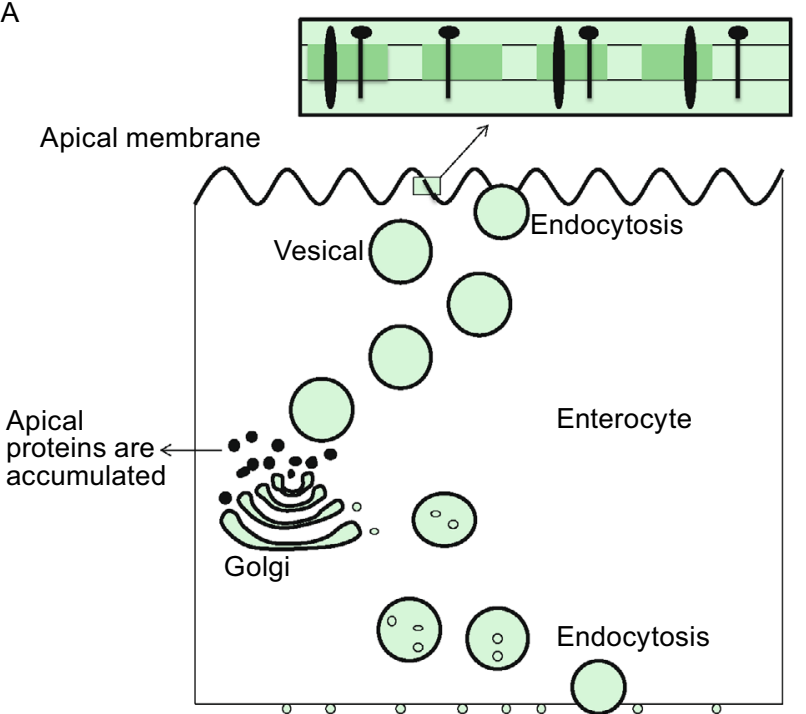

Basolateral membrane
B
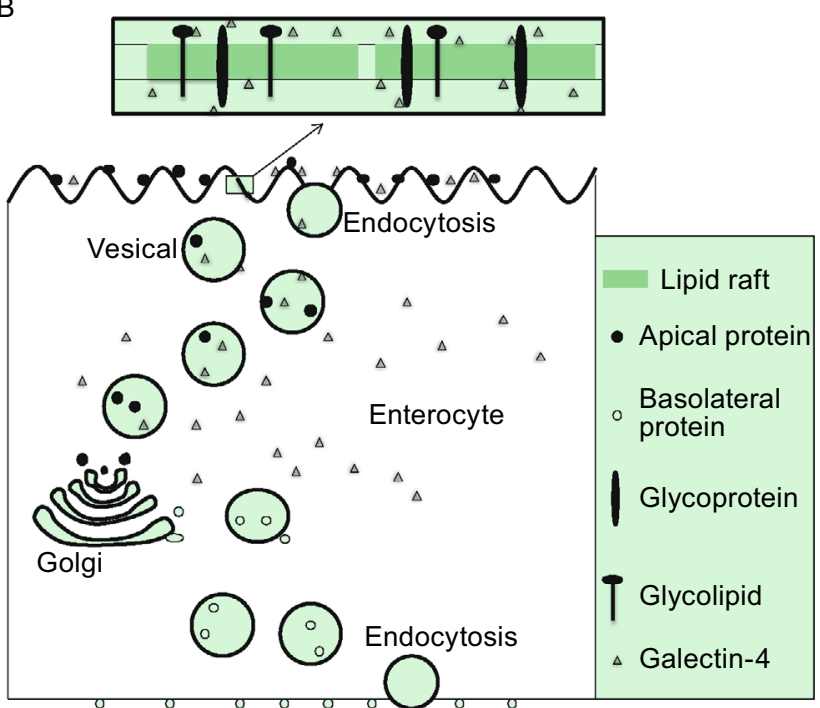

Figure 1. Galectin-4 participates in apical proteins trafficking and lipid raft stabilization. (A) In the absence of galectin-4, the apical proteins are accumulated intracellularly. Lipid rafts are small in the plasma membrane, containing only a subset of glycoproteins and glycolipids. (B) In the presence of galectin-4, apical proteins are trafficked to the apical plasma membrane. Lipid rafts are capable of clustering based on galectin- 4 crosslinking to glycoproteins and glycolipids in DRMs.

protein targeting which is determined by apical and basolateral sorting signals (Mostov et al., 2000). The sorting signals are capable of deciding which vesicle the proteins could move into, then guiding these proteins to the apical or basolateral membrane. The basolateral targeting signals are regulated by tyrosine residues existed in the cytoplasmic domain of proteins (Matter and Mellman, 1994). However, signals for apical trafficking seem more diversified because various signals have been found in cytoplasmic, transmembrane or extracellular domains (Schuck and Simons 2004).

Surprisingly, in galectin-4-knockdown HT-29 5M12 cells, the apical proteins, including mucin-1 (MUC1), sialyltransferase, dipeptidylpeptidase-IV (DPP-IV), nonspecific crossreacting antigen (NCA), carcino-embryonic antigen (CEA), and the glycosyl-phosphatidylinositol (GPI)-anchored complement regulatory protein (CD59), are found depleted in DRMs (Delacour et al., 2005, Stechly et al., 2009), which implies that galectin-4 may function as the carrier of glycoproteins trafficking. Complex-type $\mathrm{N}$-glycans have been shown to function as an apical sorting signal and it's recognition by galectin-4 has emerged as a novel apical sorting mechanism (Morelle et al., 2009). Complex-type $\mathrm{N}$-glycans, which are rich in DRMs, are composed of branched $\mathrm{N}$-acetyllactosamine (ligand of galectin-4) and hybridtype structures. Moreover, it has been proved that complextype $\mathrm{N}$-glycans could enhance the binding affinity of galectins to glycoproteins (Hirabayashi et al., 2002). Interestingly, if $\mathrm{N}$-glycans do not form complex-type, the apical glycoproteins would be delivered to the basolateral membrane in HT$295 \mathrm{M} 12$ cells (Stechly et al., 2009).
Glycoproteins are sorted in the trans-Golgi network (TGN) into carriers that take them directly to the apical side in the presence of galectin-4 (Fig. 1B), while apical proteins accumulate intracellularly in the absence of galectin-4 (Fig. 1A). The delivery of galectin-4 at a post-Golgi level is required for the recruitment of glycoproteins within lipid rafts and their apical trafficking (Stechly et al., 2009). In addition, galectin-4 was also found in post-Golgi carrier vesicles to meet the newly synthesized apical glycoproteins (Delacour et al., 2005). Because of the special affinity to glycoproteins, galectin-4 may act as a tractor to pull them into the vesicles. In the process of apical trafficking, an apical endocytic-recycling pathway of galectin-4 is required, that is to say, galectin-4 endocytosed into cells to transport glycoproteins back to apical surface (Stechly et al., 2009).

\section{Galectin-4 has bactericidal activity against bacteria expressing blood group antigens}

The bacteria that express blood group antigen may lead to generating self-specific antibodies to these antigens, which eventually causes immunological disorder. The carbohydrate structures of $A B O(H)$ antigens are composed of distinct monosaccharides on the terminal structures of glycans (Yamamoto et al., 1990). This suggests that the immunity toward pathogens expressing blood group antigens must has the ability to recognize carbohydrates. Galectins are multifunctional proteins that act as regulators of various biological processes via protein-glycan interactions. Notably, previous study suggests that galectin- 4 and galectin- 8 could 
recognize and bind to blood group antigens, as along with various other saccharides ligands (Stowell et al., 2010; Liu and Bevins, 2010).

CRD2 in galectin-4 can tightly bind to blood group B carbohydrates which are expressed by some bacteria on the side chains of surface lipopolysaccharides. An antigen on the surface of Escherichia coli ( $E$. coli) 086 is identical to human blood group $B$ antigen, thus indicating that galectin-4 could also bind to $E$. coli 086 (Andersson et al., 1989). Once binding to bacterial surface carbohydrates, galectin-4 directly kills E. coli O86 via destroying membrane integrity and bacterial motility (Stowell et al., 2010). Electron microscopy data showed that the formation of surface blebs along with disruption of $E$. coli membrane, suggesting that galectin-4 might kill the bacteria through increasing the expression of defensins (Lehrer et al., 1989). Notably, although galectin-4 could recognize human blood erythrocytes, it did not destroy the membrane integrity of these cells (Stowell et al., 2010). However, similar to other innate immune effectors, the bactericidal activity of galectin-4 is not highly specific for the blood group $B$ antigen, but also for $\alpha-1$, 3-galactose, which is another surface carbohydrate that expressed by $E$. coli (Liu and Bevins, 2010). Taken together, the binding of galectin-4 with the blood group B-related antigen expressed on bacteria causes the formation of blebs, thus leading to the death of $E$. coli O86. Up to now, the mechanism of the formation of blebs is not investigated yet.

\section{Galectin-4 promotes intestinal wound healing}

The impaired integrity of the mucosal epithelial barrier is found not only in inflammatory bowel disease (IBD) but also in other intestinal disorders, such as peptic ulcer, intestinal infections, bowel perforation, and some other diseases. Initially, cell migration is required for restitution of the impaired mucosal epithelial barrier in the intestinal lumen. The process that the epithelial cells adjacent to the injured surface move and cover the impaired area is an important initial step. Galectin-4 was shown to have the ability to enhance epithelial cell moving to this area through binding to cadherin/catenin complex at the surface of epithelial cells (Paclik et al., 2008b). However, galectin-4 mediates the intestinal epithelial migration through an unknown mechanism. Besides migration, other processes such as the proliferation, subsequent maturation and differentiation of these cells are depicted as other important step to replenish the decreased cell pool (Dignass, 2001; Wilson and Gibson, 1997). Galectin-4 was shown to enhance the expression of cyclin $\mathrm{B} 1$, which could consequently improve cell cycle progression (Paclik et al., 2008b). In all, galectin-4 is capable of enhancing migration and proliferation, which suggest a significant role within the intestinal tract and a possible beneficial effect toward impaired epithelial barrier in intestinal. However, the precise mechanism of galectin-4 on promoting intestinal wound healing has not been elucidated.
Galectin-4 promotes growth of axon and myelination in neuron

As an output channel of neuron, axon is essential for nerve conduction and rapid transmission of nerve impulses. Galectin-4 in neuron is required for axon growth (Storan et al., 2004; Velasco et al., 2013). It was proved to promote the growth of axon through increasing the cluster number and size presence of neural cell adhesion molecule (NCAM) L1 in axon membrane (Velasco et al., 2013). NCAM L1, an axonal glycoprotein expressed by many postmitotic neurons, regulates neurite outgrowth, nerve conduction and branching through L1-L1 homophilic interactions (Cheng and Lemmon, 2004; Cheng et al., 2005). Galectin-4 promotes L1 membrane cluster organization through specially binding to $\mathrm{N}$-acetyllactosamine (LacNAc) at branch ends of L1 N-glycans, which act as the regulator of the process of axonal transport of synaptic glycoproteins (Velasco et al., 2013). Therefore, galectin-4 is crucial for proper organization and function of L1 in central nervous system (CNS).

Moreover, galectin-4 also plays an important role in the regulation of myelination of axons, and its expression is downregulated at the onset of myelination (Stancic et al., 2012). Myelin, synthesized by oligodendrocytes (OLGs), is the lipid-rich membrane that specially wraps nerve axons, thereby forming a multilamellar insulating sheath, which shows plasticity and high cognitive functions in CNS (Nave, 2010). According to the role of galectin-4 in CNS, we summarized the process of myelination into three sections: 1 , galectin- 4 could be expressed and released by nonmyelinated neurons, and then bound to cell surface receptors expressed by premyelinating OLGs (Stancic et al., 2012). Upon binding to the receptors, galectin-4 could promote partly the dedifferentiation and proliferation of OLGs (Stancic et al., 2012). 2, galectin-4 expressed in OLGs promotes myelin basic protein (MBP) gene expression possibly through shifting from a cytoplasmic to a nuclear localization during the maturation of OLGs. MBP, located in the myelin serosal surface, is the major protein of the myelin sheath and maintains the stability of the structure and function of CNS myelin. Galectin-4 was thought to regulate the expression of MBP through alternate binding to the glycosylated moiety of transcription factor Sp1 and, then promoting the stability and possibly nuclear localization of Sp1 (Wei et al., 2007). Sp1 could activate the MBP promoter in nucleus of OLGs (Tretiakova et al., 1999; Wei et al., 2003). 3, the expression of galectin-4 was downregulated at the onset of myelination, therefore offering a condition for the differentiation and maturation of OLGs. The mature OLGs could wrap axons with their own cell membrane in a spiral shape, eventually contributing to the formation of myelin sheath. Recently, the sulfatide, which is a high-affinity ligand for galectin-4, has been considered as an inhibitor of sulfatide axon outgrowth, leading to a hypothesis that galectin- 4 may regulate myelination through interaction with sulfatide (Winzeler et al., 2011). Taken together, galectin-4 in neuron acts as a novel 


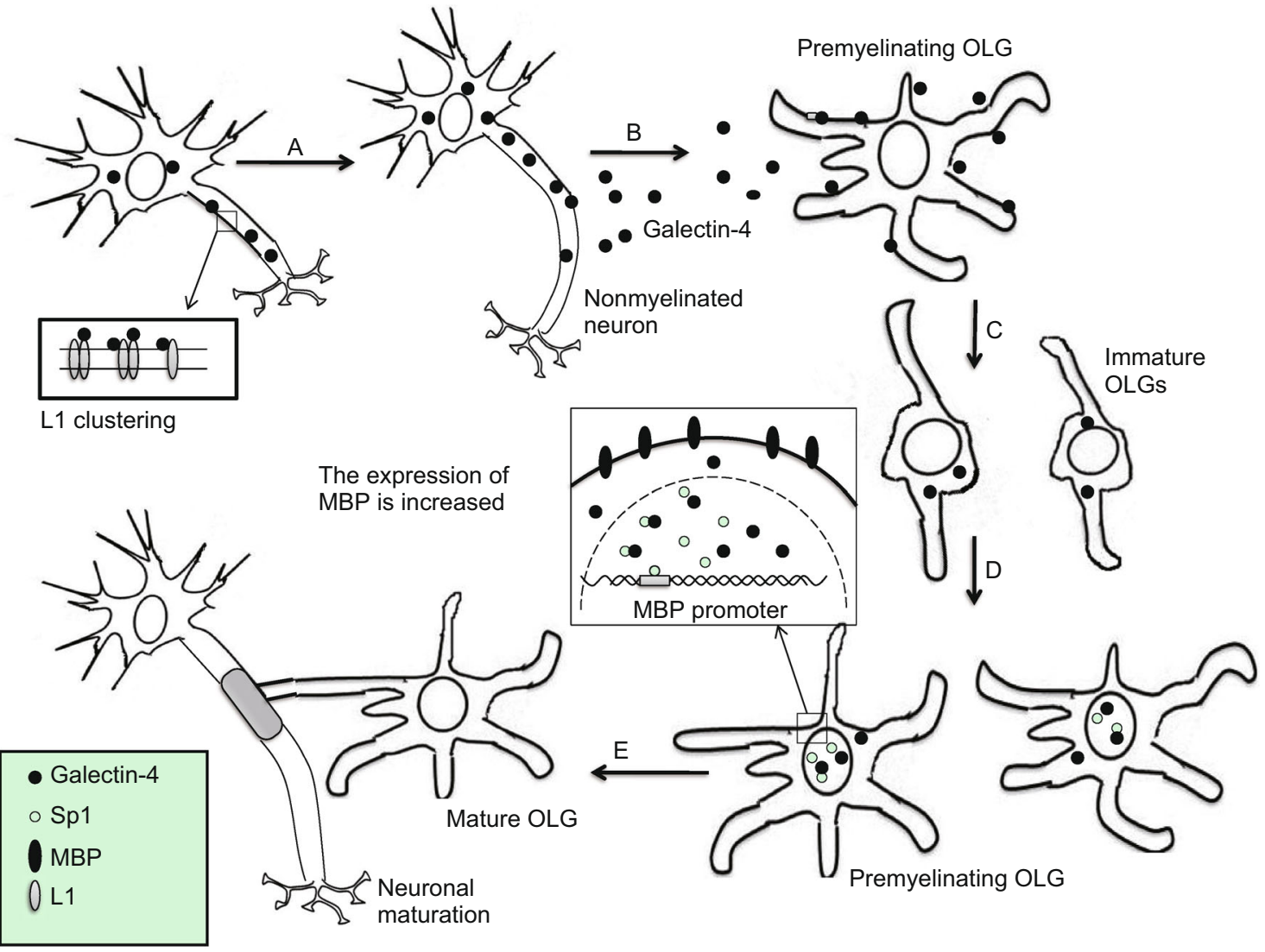

Figure 2. Galectin-4 promotes growth of axon and myelination in neuron. (A) Galectin-4 promotes outgrowth of axon through promoting L1 clustering. (B) Galectin-4 is released by nonmyelinated neurons and binds to the cell surface receptors that expressed by premyelinating OLGs. (C) Galectin-4 inhibits OLGs maturation and promotes OLGs dedifferentiation along with proliferation. (D) Immature OLGs start to differentiate. Once galectin-4 binding to the glycosylated Sp1, the stability and possibility nuclear localization of Sp1 would be increased, then leading to the upregulation of MBP gene expression. (E) Mature OLGs make the formation of myelin sheath by wrapping axons with their own cell membrane in a spiral shape.

negative regulator of OLG differentiation, and from another point of view, galectin-4 promotes the axonal myelination in CNS (Fig. 2).

\section{LGALS4 GENE AND REGULATION OF GALECTIN-4 EXPRESSION}

Galectin-4 is coded by the single gene LGALS4 that is numbered consistently with the proteins (Mehrabian et al., 1993; Barondes et al., 1994). Human LGALS4 region locates in q13.1-13.3 on chromosome 19, while mouse LGALS4 is about 3.2 centimorgans proximal to the $a p o E$ gene on chromosome 7 (Gitt et al., 1998). The coding sequence of galectin-4 is specified by nine exons and the transcript length is $1 \mathrm{~kb}$. The main transcriptional start site of human LGALS4 was found at position-55 nt, which is 33 bases downstream from a near consensus TATA box and its upstream promoter elements contain HNF-4, MyoD, c-Rel, $\mathrm{HNF}-3 \beta$, CAAT enhancer binding protein (C/EBP), and HFH2 (Huflejt and Leffler, 2003).
$\mathrm{HFH}-2, \mathrm{HNF}-4$, and HNF-3 $\beta$ are members of the Hepatocyte Nuclear Factor 3 (HNF-3)/fork family of transcription factors (Ye et al., 1997), which contribute to the neoplastic transformation-related increases in galectin-4 mRNA expression in liver (Kondoh et al., 1999). C-Rel, a member of the NF-kB family, was aberrantly activated or expressed in human breast cancers, as well as in other solid and hematopoietic malignancies (Cogswell et al., 2000; Sovak et al., 1997). It exists either as a heterodimer or a homodimer with some NF-kB subunits and this dimmers can potently transactivate NF-kB-dependent promoters. Furthermore, c-Rel was reported to promote the formation of C/EBPcomplex and then bind to the complex (Agrawal et al., 2003). Because galectin- 4 is abnormally overexpressed in human breast cancers, as well as in other solid and hematopoietic malignancies, it may be a downstream product of the NF-KB. In addition, the twin single nucleotide polymorphisms (SNPs) could potentially be related to galectin-4 upregulation via deletion and insertion of new transcription factor binding sites in colorectal cancer (CRC) (Helwa, 2010). 


\section{THE ROLE OF GALECTIN-4 IN INFLAMMATORY AND CANCER DISEASES}

\section{Galectin-4 and intestinal inflammation}

IBD is known as a chronic intestinal inflammatory condition that is characterized by two forms of intestinal inflammation: Crohn's disease (CD) and ulcerative colitis (UC) (Podolsky, 1991). Both of the two diseases are correlated to the activation of inflammatory memory $\mathrm{CD} 4^{+} \mathrm{T}$ cells in the inflamed gastrointestinal tract (Xavier and Podolsky, 2007). Currently, IBD is presumed to be a result of the complex effect of genetic factors, microbial agents, humoral immunity and environmental factors. Thus, healing of the intestinal surface epithelium is regarded as a complex network of various factors. Galectin-4 is an important factor that is related to the mucosal immunity.

Galectin-4 was demonstrated to exacerbate intestinal inflammation by directly stimulating the $\mathrm{CD} 4^{+} \mathrm{T}$ cells to produce IL-6 on TCR mutational colitis model (Hokama et al., 2004). IL6, a well-known inflammatory cytokine, could exacerbate intestinal inflammation in the presence of impaired mucosal barrier or injury to the mucosa. In addition, IL-6 was also confirmed to increase the expression of B-cell lymphoma-2 (Bcl-2) and $\mathrm{B}$-cell lymphoma-extra large (Bcl-xl) through activating the STAT3 signal pathway, thus inhibiting the apoptosis of CD4 ${ }^{+} \mathrm{T}$ cells, and then leading to sustainable development of IBD (Atreya et al., 2000; Allocca et al., 2013; Waldner and Neurath, 2014). Galectin-4 may directly interact with the CD4 ${ }^{+}$T cells through binding to the immunological synapse, which is a specific activator of the protein kinase C (PKC) $\theta$-associated signaling cascade in lipid raft (Hokama et al., 2004; Nagahama et al., 2008). Through activating the PKC-associated pathway, galectin-4 stimulates the production of IL-6, therefore exacerbates intestinal inflammation. However, it is not confirmed which receptor on intestinal CD4 ${ }^{+}$T cells specifically crosslinks with galectin-4. Lately, an inducible colitis-associated glycome (CAG), which contains an immature (nonsialylated) core-1 O-glycan expressed by $\mathrm{CD} 4^{+}$T cells, was identified as a ligand of galectin-4 under intestinal inflammatory conditions (Nishida et al., 2012). Thus, galectin- 4 may activate the PKC $\theta$ by binding to $C A G$ and, then contributing to exacerbation of colitis. In consistent with this, galectin-4, which shows a high affinity to immature O-glycan (Ideo et al., 2002; Blixt et al., 2004), has been shown to exacerbate an experimental chronic colitis (Hokama et al., 2004).

However, Paclik D et al. demonstrated that galectin-4 could induce Tcell apoptosis by binding to the CD3 epitope at Tcells surface on wild-type colitis model. Once binding to this epitope, galectin-4 promotes apoptosis of T cells in calpain-dependent manner and reduces the secretion of cytokines including IL-6, IL-8, IL-10, and IL-17, and then ameliorating the inflammation (Paclik et al., 2008a). Lately, another research found that the role of galectin- 4 varied in different experimental colitis models (Mathieu et al., 2008). Based on the existing data, we can conclude that galectin-4 may exacerbate intestinal inflammation in TCR mutational colitis model, while ameliorate intestinal inflammation in wild-type colitis model (Fig. 3). Further studies are required to ascertain the universal role of galectin-4 in intestinal inflammation.

\section{Galectin-4 and cancer}

Galectin-4 which has been detected in many cancers has association with the development and progression of pancreatic carcinoma, hepatocellular carcinoma, colorectal cancer (CRC), breast carcinoma, gastric cancer, and lung cancer (Rechreche et al., 1997; Hippo et al., 2001; Hayashi et al., 2013; Belo et al., 2013; Cai et al., 2014). However, it plays contradictory roles in different type of cancer cells. Furthermore, it has been detected in serum of some cancer patients (Kim et al., 2013; Cai et al., 2014; Barrow et al., 2011; Barrow et al., 2013). Up to now, although there is a number of published data regarding galectin- 4 expression in cancer, the available information is remained limited. Among these cancers, only the role of galectin- 4 in CRC development has been revealed explicitly.

\section{The role of intracellular galectin-4 in cancer}

In CRC, expression of galectin-4 was dramatically decreased compared to normal colon tissues and this condition promoted tumour progression and metastasis (Rechreche et al., 1997; Satelli et al., 2011; Kim et al., 2013). Lower expression of galectin-4 in CRC cells could induce increased cell proliferation, migration and motility. Galectin- 4 was found to inhibit tumorigenesis of CRC cells through Wnt/ $\beta$-catenin signaling pathway and IL-6/NF-KB/STAT3 signaling pathway (Satelli et al., 2011; Kim et al., 2013). In CRC cells, galectin-4 could cross-link Wnt signaling pathway proteins (APC, axin, and $\beta$ catenin), thereby stabilizing the destruction complex, and promoting degradation of $\beta$-catenin in cytoplasm (Satelli et al., 2011). Therefore, $\beta$-catenin could not enter into nucleus to activate the Wnt target genes, which results in the downregulation of cyclin D1, p21, and p15, and the inhibition of cell proliferation, migration, and motility. In addition, galectin-4 has been confirmed to downregulate IL-6, which in turn simultaneously inhibits the activation of nuclear factor-kappa B (NF$\mathrm{KB})$ and signal transducer and activator of transcription 3 (STAT3) in CRC (Kim et al., 2013; Lang et al., 2007). Upon suppressing of the IL-6/NF-KB/STAT3 signaling pathway, the level of vascular endothelial growth factor (VEGF), cyclooxygenase-2 (COX-2), and other genes involved in tumorigenesis would be downregulated, thereby inhibiting tumor progression.

A similar mechanism in pancreatic cancer was observed by Maftouh et al., 2014, where decreased levels of $\beta$-catenin were found in pancreatic cancer cells when in the presence of galectin-4. Their results coupled, therefore, the mechanism to a decreased Wnt signaling in the presence of galectin-4. Similarly, in hepatocellular cancer, the low level expression of galectin-4 contributes to increased metastasis and progression of the cancer (Cai et al., 2014). In addition, decreased 


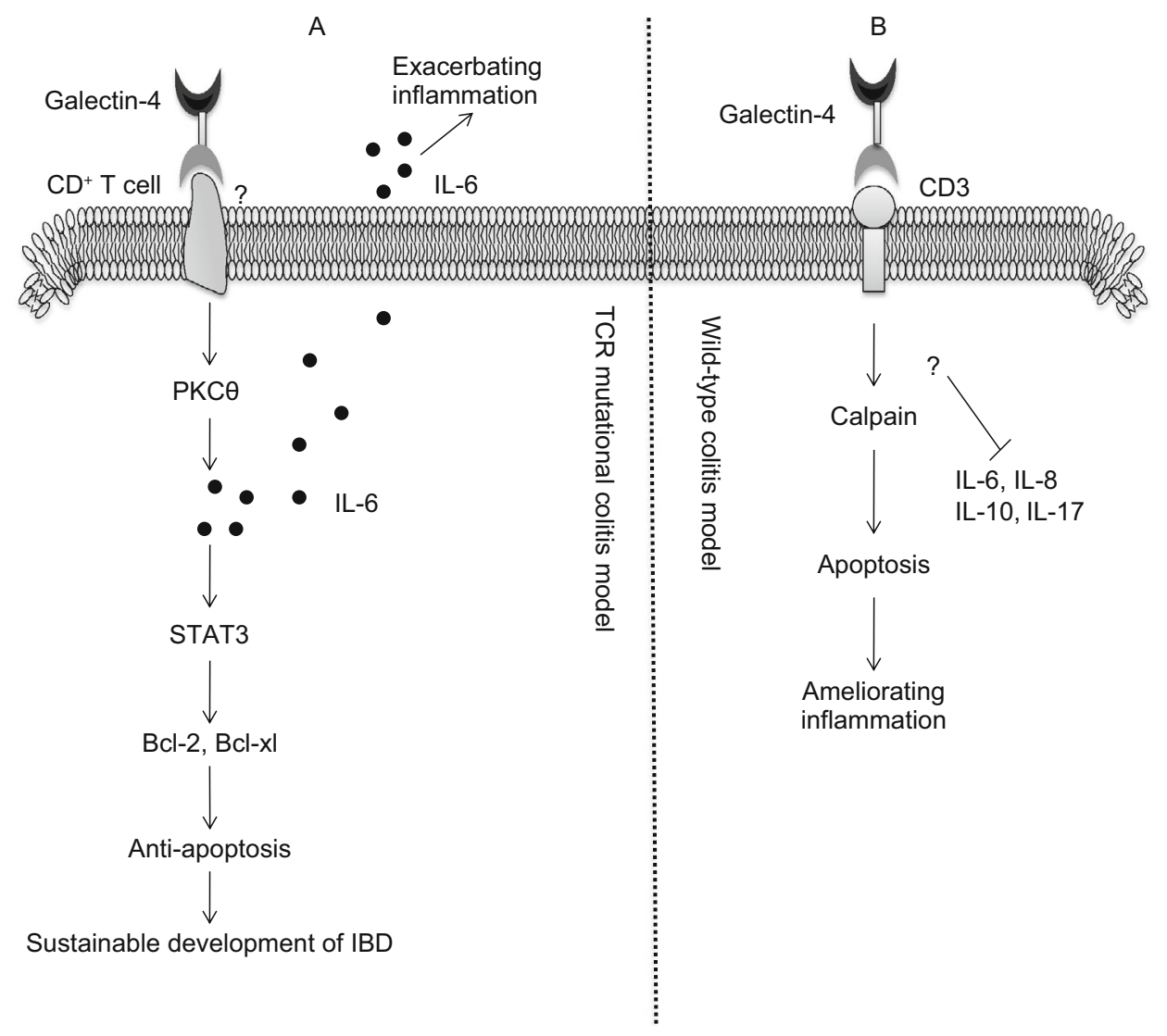

Figure 3. The different molecular mechanism of galectin-4 in exacerbating or ameliorating inflammation. (A) (Exacerbating inflammation): Through binding to the receptor (may be CAG) expressed by CD $4^{+}$T cells, galectin- 4 stimulates the production of IL- 6 on TCR mutational colitis model. IL-6 could directly exacerbate IBD and inhibiting the apoptosis of CD4 ${ }^{+}$T cells by activating STAT3 pathway, which eventually leading to sustainable development of IBD. (B) (Ameliorating inflammation): Galectin-4 ameliorates IBD through inducing apoptosis of T cell and reducing the secretion of inflammatory cytokines (IL-6, IL-8, IL-10, and IL-17) on wild-type colitis model.

expression of galectin-4 was observed in metastatic ileal carcinoids compared with primary carcinoid tumors in the ileum, indicating that galectin-4 may act as a tumor suppressor in ileal carcinoids (Rumilla et al., 2006). Conversely, in lung and gastric cancer, high level expression of galectin-4 was demonstrated to be an independent predictor for metastasis and correlated with poor clinical outcomes (Hayashi et al., 2013; Hippo et al., 2001). Taken together, galectin-4 acts as a tumor suppressor in CRC, pancreatic cancer, hepatocellular cancer, and ileal carcinoids, whereas galectin-4 functions as a tumor promoter in lung and gastric cancer.

The role of galectin-4 in serum of cancer patients in cancer

The free circulating level of galectin-4 in serum was significantly higher in patients with colon, hepatocellular, and breast cancer, in particular, those with metastasis (Barrow et al., 2011; Barrow et al., 2013; Kim et al., 2013; Cai et al., 2014). The expression level of galectin- 4 was observed to be significantly increased up to 31-fold in the serum of colorectal cancer patients compared with healthy control group. Galectin-4 promotes cancer cell adhesion to vascular endothelial cells by interaction with the Thomsen-Friedenreich (TF) disaccharide on cancer-associated MUC1 (Barrow et al., 2011). As previously shown for galectin-3, this interaction causes MUC1 cell surface polarization, thus leading to exposure of underlying adhesion molecules that promote cancer-endothelium adhesion (Zhao et al., 2009), which indicates a metastasis-promoting effect. Furthermore, the interaction of galectin- 4 with the vascular endothelium contributes to the increased circulating level of some cytokines and chemokines, including monocyte chemotatic protein 1 (MCP-1), granulocyte colony-stimulating factor (G-CSF) and IL-6 (Chen et al., 2014). Therefore, circulating level of galectin-4 might be a predictor for cancer patients, especially those with metastasis. However, no significant correlation between cancer stages and the level of circulating galectin-4 was observed in the serum of breast and colorectal cancer patients (Barrow et al., 2011). 


\section{CONCLUSION REMARKS}

Recent investigations of the molecular structure and physiological functions of galectin-4 have significantly increased our understanding of the potential roles of galectin- 4 in some diseases, such as intestinal inflammation, tumors, etc. With further investigation of the effects and underlying mechanism, galectin- 4 could be presented as a useful therapeutic target for killing bacteria, wound healing, and inhibiting tumorigenesis.

Many bacteria in human serum decorate their surfaces with diverse carbohydrate structures, and parts of these structures have similarities to human antigens, which leads to a difficult utilization of drugs to kill them directly. Galectin-4 may act as an innate defense lectin by recognizing the carbohydrates on the surface of $E$. coli O86 to kill the bacteria directly. In intestinal inflammation, galectin-4 has shown an inconsistent role in regulation of T cells, so the explicitly role should be further investigated in the future. Intracellularly, galectin-4 functions as a tumor suppressor, and its downregulation is an important event in the tumorigenesis of CRC, pancreatic cancer, and hepatocellular cancer, whereas it functions conversely in lung cancer and gastric cancer. Moreover, the expression of galectin-4 might be a biomarker in serum of colon and breast cancer patients. Although galectin-4 is not a universal and unambiguous marker in different types of cancers, it could be a helpful parameter in diagnosis of these tumors and clinical manifestations.

\section{ACKNOWLEGEMENTS}

This work was funded by the National Natural Science Foundation of China (Grant No. 81373450) and Shandong Province Science and Technology Key Project (2014GSF118032).

\section{ABBREVIATIONS}

CAG, colitis-associated glycome; CD, Crohn's disease; CEA, carcinoembryonic antigen; C/EBP, CAAT enhancer binding protein; CNS, central nervous system; COX-2, cyclooxygenase-2; CRC, colorectal cancer; CRD, carbohydrate-recognition domains; DPP-IV, dipeptidylpeptidase-IV; DRMs, detergent-resistant membranes; G-CSF, granulocyte colony-stimulating factor; GPI, glycosyl-phosphatidylinositol; IBD, inflammatory bowel disease; MBP, myelin basic protein; MCP1, monocyte chemotatic protein 1; MUC1, mucin-1; NCA, nonspecific cross-reacting antigen; NCAM, neural cell adhesion molecule; NF-kb, nuclear factor-kappa B; OLGs, oligodendrocytes; PKC, protein kinase C; SNPs, single nucleotide polymorphisms; STAT3, signal transducer and activator of transcription 3; TGN, trans-Golgi network; UC, ulcerative colitis; VEGF, vascular endothelial growth factor

\section{COMPLIANCE WITH ETHICS GUIDELINES}

Zhan-Qi Cao and XiuLi Guo declare that they have no conflict of interest. This article does not contain any studies with human or animal subjects performed by the any of the authors.

\section{OPEN ACCESS}

This article is distributed under the terms of the Creative Commons Attribution 4.0 International License (http://creativecommons.org/ licenses/by/4.0/), which permits unrestricted use, distribution, and reproduction in any medium, provided you give appropriate credit to the original author(s) and the source, provide a link to the Creative Commons license, and indicate if changes were made.

\section{REFERENCES}

Agrawal A, Samols D, Kushner I (2003) Transcription factor c-Rel enhances $\mathrm{C}$-reactive protein expression by facilitating the binding of C/EBP $\beta$ to the promoter. Mol Immunol 40:373-380

Allocca M, Jovani M, Fiorino G, Schreiber S, Danese S (2013) AntiIL-6 treatment for inflammation bowel disease: next cytokine, next target. Curr Drug Target 12:1508-1521

Andersson M, Carlin N, Leontein K, Lindquist $U$, Slettengren $\mathrm{K}$ (1989) Structural studies of the O-antigenic polysaccharide of Escherichia coli O86, which possesses blood-group B activity. Carbohydr Res 185:211-223

Atreya R, Mudter J, Finotto S, Müllberg J, Jostock T, Wirtz S, Schütz M, Bartsch B, Holtmann M, Becker C et al (2000) Blockade of interleukin 6 trans signaling suppresses T-cell resistance against apoptosis in chronic intestinal inflammation: evidence in crohn disease and experimental colitis in vivo. Nat Med 6:583-588

Barondes SH, Castronovo V, Cooper DN, Cummings RD, Drickamer K, Feizi T, Gitt MA, Hirabayashi J, Hughes C, Kasai K et al (1994) Galectins: a family of animal pgalactoside-binding lectins. Cell 76:597-598

Barrow H, Guo X, Wandall HH, Pedersen JW, Fu B, Zhao Q, Chen C, Rhodes JM, Yu LG (2011) Serum galectin-2, -4 , and -8 are greatly increased in colon and breast cancer patients and promote cancer cell adhesion to blood vascular endothelium. Clin Cancer Res 17:7035-7046

Barrow H, Rhodes JM, Yu LG (2013) Simultaneous determination of serum galectin-3 and -4 levels detects metastases in colorectal cancer patients. Cell Oncol 36:9-13

Belo Al, van der Sar AM, Tefsen B, van Die I (2013) Galectin-4 reduces migration and metastasis formation of pancreatic cancer cells. PLoS One 8:e65957

Blixt O, Head S, Mondala T, Scanlan C, Huflejt ME, Alvarez R, Bryan MC, Fazio F, Calarese D, Stevens J et al (2004) Printed covalent glycan array for ligand profiling of diverse glycan binding proteins. Proc Natl Acad Sci USA 101:17033-17038

Brewer FC (2002) Binding and cross-linking properties of galectins. Biochim Biophys Acta 1572:255-262

Brewer CF, Miceli MC, Baum LG (2002) Clusters, bundles, arrays and lattices: novel mechanisms for lectin-saccharide-mediated cellular interactions. Curr Opin Struct Biol 12:616-623

Bum-Erdene K, Leffler H, Nilsson UJ, Blanchard H (2015) Structural characterization of human galectin-4 C-terminal domain: elucidating the molecular basis for recognition of glycosphingolipids, sulfated saccharides and blood group antigens. FEBS J 282:3348-3367 
Cai Z, Zeng Y, Xu B, Gao Y, Wang S, Zeng J, Chen L, Huang A, Liu XL, Liu JF (2014) Galectin-4 serves as a prognostic biomarker for the early recurrence/metastasis of hepatocellular carcinoma. Cancer Sci 105:1510-1517

Chen C, Duckworth CA, Fu B, Pritchard DM, Rhodes JM, Yu LG (2014) Circulating galectins $-2,-4$ and -8 in cancer patients make important contributions to the increased circulation of several cytokines and chemokines that promote angiogenesis and metastasis. Br J Cancer 110:741-752

Cheng L, Lemmon V (2004) Pathological missense mutations of neural cell adhesion molecule L1 affect neurite outgrowth and branching on an L1 substrate. Mol Cell Neurosci 27:522-530

Cheng L, Itoh K, Lemmon V (2005) L1-mediated branching is regulated by two ezrin-radixin-moesin (ERM)-binding sites, the RSLE region and a novel juxtamembrane ERM-binding region. J Neurosci 25:395-403

Cogswell PC, Guttridge DC, Funkhouser WK, Baldwin JA (2000) Selective activation of NF-kappa B subunits in human breast cancer: potential roles for NF-kappa B2/p52 and for Bcl-3. Oncogene 19:1123-1131

Cooper DN (2002) Galectinomics: finding themes in complexity. Biochim Biophys Acta 1572:209-231

Cooper DN, Barondes SH (1999) God must love galectins; he made so many of them. Glycobiology 9:979-984

Danguy A, Camby I, Kiss R (2002) Galectins and cancer. Biochim Biophys Acta 1572:285-293

Danielsen EM, Hansen GH (2008) Lipid raft organization and function in the small intestinal brush border. J Physiol Biochem 64:377-382

Danielsen EM, van Deurs B (1997) Galectin-4 and small intestinal brush border enzymes form clusters. Mol Biol Cell 8:2241-2251

Delacour D, Gouyer V, Zanetta JP, Drobecq H, Leteurtre E, Grard G, Moreau-Hannedouche O, Maes E, Pons A, Andre S et al (2005) Galectin-4 and sulfatides in apical membrane trafficking in enterocyte-like cells. J Cell Biol 169:491-501

Dignass AU (2001) Mechanisms and modulation of intestinal epithelial repair. Inflamm Bowel Dis 7:68-77

Gitt MA, Xia YR, Atchison RE, Lusis AJ, Barondes SH, Leffler H (1998) Sequence, structure, and chromosomal mapping of the mouse Lgals6 gene, encoding galectin-6. J Biol Chem 273:29612970

Hayashi T, Saito T, Fujimura T, Hara K, Takamochi K, Mitani K, Mineki R, Kazuno S, Oh S, Ueno T et al (2013) Galectin-4, a novel predictor for lymph node metastasis in lung adenocarcinoma. PLoS One 8:e81883

Helwa R (2010) Functional studies on the galectin-4 promoter and its use for establishing a transcription factors array assay. Dissertation, Ruperto-Carola University of Heidelberg, Heidelberg, pp 1-111

Hippo Y, Yashiro M, Ishii M, Taniguchi H, Tsutsumi S, Hirakawa K, Kodama T, Aburatani $\mathrm{H}$ et al (2001) Differential gene expression profiles of scirrhous gastric cancer cells with high metastatic potential to peritoneum or lymph nodes. Cancer Res 61:889-895

Hirabayashi J, Hashidate T, Arata Y, Nishi N, Nakamura T, Hirashima M, Urashima T, Oka T, Futai M, Muller WE et al (2002) Oligosaccharide specificity of galectins: a search by frontal affinity chromatography. Biochim Biophys Acta 1572:232-254
Hokama A, Mizoguchi E, Sugimoto K, Shimomura Y, Tanaka Y, Yoshida M, Rietdijk ST, de Jong YP, Snapper SB, Terhorst C et al (2004) Induced reactivity of intestinal CD4+ T cells with an epithelial cell lectin, galectin-4, contributes to exacerbation of intestinal inflammation. Immunity 20:681-693

Hokama A, Mizoguchi E, Mizoguchi A (2008) Roles of galectins in inflammatory bowel disease. World J Gastroenterol 14:5133

Huflejt ME, Leffler H (2003) Galectin-4 in normal tissues and cancer. Glycoconj J 20:247-255

Huflejt ME, Jordan ET, Gitt MA, Barondes SH, Leffler H (1997) Strikingly different localization of galectin-3 and galectin- 4 in human colon adenocarcinoma T84 cells. Galectin-4 is localized at sites of cell adhesion. J Biol Chem 272:14294-14303

Ideo H, Seko A, Ohkura T, Matta KL, Yamashita K (2002) Highaffinity binding of recombinant human galectin-4 to SO3- $\rightarrow$ 3Galß1 $\rightarrow$ 3GalNAc pyranoside. Glycobiology 12:199-208

Ideo H, Seko A, Yamashita K (2005) Galectin-4 binds to sulfated glycosphingolipids and carcinoembryonic antigen in patches on the cell surface of human colon adenocarcinoma cells. J Biol Chem 280:4730-4737

Ideo H, Seko A, Yamashita K (2007) Recognition mechanism of galectin-4 for cholesterol 3-sulfate. J Biol Chem 282:2108121089

Ideo H, Hoshi I, Yamashita K, Sakamoto M (2013) Phosphorylation and externalization of galectin-4 is controlled by Src family kinases. Glycobiology 23:1452-1462

Jiang W, Puch S, Guo X, Bhavanandan VP (1999) Signature sequences for the galectin-4 subfamily. IUBMB Life 48:601-605

Kim SW, Park KC, Jeon SM, Ohn TB, Kim TI, Kim WH, Cheon JH (2013) Abrogation of galectin-4 expression promotes tumorigenesis in colorectal cancer. Cell Oncol 36:169-178

Kondoh N, Wakatsuki T, Ryo A, Hada A, Aihara Horiuchi S, Goseki N, Matsubara O, Takenaka K, Shichita M et al (1999) Identification and characterization of genes associated with human hepatocellular carcinogenesis. Cancer Res 59:4990-4996

Lang SA, Moser C, Gaumann A, Klein D, Glockzin G, Popp FC, Dahlke MH, Piso P, Schlitt HJ, Geissler EK et al (2007) Targeting heat shock protein 90 in pancreatic cancer impairs insulin-like growth factor-I receptor signaling, disrupts an interleukin-6/signaltransducer and activator of transcription 3/hypoxia-inducible factor- $1 \alpha$ autocrine loop, and reduces orthotopic tumor growth. Clin Cancer Res 13:6459-6468

Leffler H, Masiarz FR, Barondes SH (1989) Soluble lactose-binding vertebrate lectins: a growing family. Biochemistry 28:9222-9229

Lehrer RI, Barton A, Daher KA, Harwig SS, Ganz T, Selsted ME (1989) Interaction of human defensins with Escherichia coli. Mechanism of bactericidal activity. J Clin Investig 84:553

Liu FT, Bevins CL (2010) A sweet target for innate immunity. Nat Med 16:263-264

London E, Brown DA (2000) Insolubility of lipids in triton X-100: physical origin and relationship to sphingolipid/cholesterol membrane domains (rafts). Biochim Biophys Acta 1508:182-195

Maftouh M, Belo Al, Avan A, Funel N, Peters GJ, Giovannetti E, van Die I (2014) Galectin-4 expression is associated with reduced lymph node metastasis and modulation of Wnt/ $\beta$-catenin signalling in pancreatic adenocarcinoma. Oncotarget 5:5335 
Marková V, Smetana K, Jeníková G, Láchová J, Krejciríková V, Poplstein M, Fabry M, Brynda J, Alvarez RA, Cummings RD, Maly $P$ (2006) Role of the carbohydrate recognition domains of mouse galectin-4 in oligosaccharide binding and epitope recognition and expression of galectin- 4 and galectin- 6 in mouse cells and tissues. Int $\mathrm{J}$ Mol Med 18:65-76

Mathieu A, Nagy N, Decaestecker C, Ferdinande L, Vandenbroucke K, Rottiers P, Cuvelier CA, Salmon I, Demetter P (2008) Expression of galectins $-1,-3$ and -4 varies with strain and type of experimental colitis in mice. Int J Exp Pathol 89:438-446

Matter K, Mellman I (1994) Mechamisms of cell polarity: sorting and transport in epithelial cells. Curr Opin Cell Biol 6:545-554

Mehrabian M, Gitt MA, Sparkes RS, Leffler H, Barondes SH, Lusis AJ (1993) Two members of the S-lac lectin gene family, LGALS1 and LGALS2, reside in close proximity on human chromosome 22q12-q13. Genomics 15:418-420

Morelle W, Stechly L, Andre S, Seuningen IV, Porchet N, Gabius HJ, Michalski JC, Huet G (2009) Glycosylation pattern of brush border-associated glycoproteins in enterocyte-like cells: involvement of complex-type $\mathrm{N}$-glycans in apical trafficking. Biol Chem 390:529-544

Mostov KE, Verges M, Altschuler Y (2000) Membrane traffic in polarized epithelial cells. Curr Opin Cell Biol 12:483-490

Nagahama K, Ogawa A, Shirane K, Shimomura Y, Sugimoto K, Mizoguchi A (2008) Protein kinase C $\theta$ plays a fundamental role in different types of chronic colitis. Gastroenterology 134:459469

Nave KA (2010) Myelination and support of axonal integrity by glia. Nature 468:244-252

Nishida A, Nagahama K, Imaeda H, Ogawa A, Lau CW, Kobayashi T, Hisamatsu T, Preffer FI, Mizoguchi E, Ikeuchi H et al (2012) Inducible colitis-associated glycome capable of stimulating the proliferation of memory CD4+ T cells. J Exp Med 209:2383-2394

Oda Y, Herrmann J, Gitt MA, Turck CW, Burlingame AL, Barondes $\mathrm{SH}$, Leffler H (1993) Soluble lactose-binding lectin from rat intestine with two different carbohydrate-binding domains in the same peptide chain. J Biol Chem 268:5929-5939

Paclik D, Danese S, Berndt U, Wiedenmann B, Dignass A, Sturm A (2008a) Galectin-4 controls intestinal inflammation by selective regulation of peripheral and mucosal $\mathrm{T}$ cell apoptosis and cell cycle. PLoS One 3:e2629

Paclik D, Lohse K, Wiedenmann B, Dignass AU, Sturm A (2008b) Galectin-2 and -4 , but not Galectin-1, promote intestinal epithelial wound healing in vitro through a TGF-beta-independent mechanism. Inflamm Bowel Dis 14:1366-1372

Pike LJ (2005) Growth factor receptors, lipid rafts and caveolae: an evolving story. Biochim Biophys Acta 1746:260-273

Podolsky DK (1991) Inflammatory bowel disease. N Engl J Med 325:928-937

Rabinovich GA (1999) Galectins: an evolutionarily conserved family of animal lectins with multifunctional properties; a trip from the gene to clinical therapy. Cell Death Differ 6:711-721

Rechreche H, Mallo GV, Montalto G, Dagorn JC, lovanna JL (1997) Cloning and expression of the mRNA of human galectin- 4 , an S-type lectin down-regulated in colorectal cancer. Eur J Biochem 248:225-230
Rumilla KM, Erickson LA, Erickson AK, Lloyd RV (2006) Galectin-4 expression in carcinoid tumors. Endocr Pathol 17:243-249

Rustiguel JK, Kumagai PS, Dias-Baruffi M, Costa-Filho AJ, Nonato MC (2015) Recombinant expression, purification and preliminary biophysical and structural studies of C-terminal carbohydrate recognition domain from human galectin-4. Protein Expr Purif 118:39-48

Satelli A, Rao PS, Thirumala S, Rao US (2011) Galectin-4 functions as a tumor suppressor of human colorectal cancer. Int $\mathrm{J}$ Cancer 129:799-809

Schuck S, Simons K (2004) Polarized sorting in epithelial cells: raft clustering and the biogenesis of the apical membrane. J Cell Sci 117:5955-5964

Simons K, Ehehalt R (2002) Cholesterol, lipid rafts, and disease. J Clin Investig 110:597-603

Sovak MA, Bellas RE, Kim DW, Zanieski GJ, Rogers AE, Traish AM, Sonenshein GE (1997) Aberrant nuclear factor-kappaB/Rel expression and the pathogenesis of breast cancer. J Clin Investig 100:2952

Stancic M, Slijepcevic D, Nomden A, Vos MJ, De Jonge JC, Sikkema AH, Gabius HJ, Hoekstra D, Baron W (2012) Galectin-4, a novel neuronal regulator of myelination. Glia 60:919-935

Stechly L, Morelle W, Dessein AF, André S, Grard G, Trinel D, Dejonghe MJ, Leteurtre E, Drobecq H, Trugnan G et al (2009) Galectin-4-regulated delivery of glycoproteins to the brush border membrane of enterocyte-like cells. Traffic 10:438-450

Storan MJ, Magnaldo T, Biol-N'Garagba MC, Zick Y, Key B (2004) Expression and putative role of lactoseries carbohydrates present on NCAM in the rat primary olfactory pathway. J Comp Neurol 475:289-302

Stowell SR, Arthur CM, Dias-Baruffi M, Rodrigues LC, Gourdine JP, Heimburg-Molinaro J, Ju T, Molinaro RJ, Rivera-Marrero C, Xia B et al (2010) Innate immune lectins kill bacteria expressing blood group antigen. Nat Med 16:295-301

Tretiakova A, Steplewski A, Johnson EM, Khalili K, Amini S (1999) Regulation of myelin basic protein gene transcription by Sp1 and Puralpha: evidence for association of Sp1 and Puralpha in brain. J Cell Physiol 18:160-168

Velasco S, Díez-Revuelta N, Hernández-lglesias T, Kaltner H, André S, Gabius HJ, Abad-Rodríguez J (2013) Neuronal Galectin-4 is required for axon growth and for the organization of axonal membrane L1 delivery and clustering. J Neurochem 125:49-62

Vokhmyanina OA, Rapoport EM, André S, Severov VV, Ryzhov I, Pazynina GV, Korchagina E, Gabius HJ, Bovin NV (2012) Comparative study of the glycan specificities of cell-bound human tandemrepeat-type galectin-4, -8 and -9. Glycobiology 22:1207-1217

Waldner MJ, Neurath MF (2014) Master regulator of intestinal disease: IL-6 in chronic inflammation and cancer development. Semin Immunol 1:75-79

Wei Q, Miskimins WK, Miskimins R (2003) The Sp1 family of transcription factors is involved in p27(Kip1)-mediated activation of myelin basic protein gene expression. Mol Cell Biol 23:4035-4045

Wei Q, Eviatar-Ribak T, Keith Miskimins W, Miskimins R (2007) Galectin-4 is involved in p27-mediated activation of the myelin basic protein promoter. J Neurochem 101:1214-1223

Wilson AJ, Gibson PR (1997) Epithelial migration in the colon: filling in the gaps. Clin Sci 93:97-108 
Winzeler AM, Mandemakers WJ, Sun MZ, Stafford M, Phillips CT, Barres BA (2011) The lipid sulfatide is a novel myelin-associated inhibitor of CNS axon outgrowth. J Neurosci 31:6481-6492

Xavier RJ, Podolsky DK (2007) Unravelling the pathogenesis of inflammatory bowel disease. Nature 448:427-434

Yamamoto FI, Clausen H, White T, Marken J, Hakomori SI (1990) Molecular genetic basis of the histo-blood group ABO system. Nature 345:229-233
Ye H, Kelly TF, Samadani U, Lim L, Rubio S, Overdier DG, Roebuck KA, Costa RH (1997) Hepatocyte nuclear factor 3/fork head homolog 11 is expressed in proliferating epithelial and mesenchymal cells of embryonic and adult tissues. Mol Cell Biol 17:1626-1641

Zhao Q, Guo X, Nash GB, Stone PC, Hilkens J, Rhodes JM, Yu LG (2009) Circulating galectin-3 promotes metastasis by modifying MUC1 localization on cancer cell surface. Cancer Res 69:67996806 